\title{
La perspectiva sociotècnica en l'anàlisi de polítiques públiques
}

\section{Marc Grau}

Lupicinio Íñiguez-Rueda

Universitat Autònoma de Barcelona. Departament de Psicologia Social

Grup d'Estudis Socials de la Ciència i la Tecnologia (GESCIT)

08193 Bellaterra (Barcelona). Spain

marc.grau@uab.cat

lupicinio.iniguez@uab.cat

\section{Joan Subirats}

Universitat Autònoma de Barcelona. Departament de Ciència Política i Dret Públic 08193 Bellaterra (Barcelona). Spain

Institut de Govern i Polítiques Públiques (IGOP)

joan.subirats@uab.cat

\section{Resum}

Aquest article explora l'interès per l'anàlisi de polítiques públiques dels diversos conceptes, instruments i plantejaments analítics que han aparegut, en els darrers anys, en la literatura al voltant de la teoria de l'actor-xarxa (ANT).

Paraules clau: anàlisi de polítiques públiques, teoria de l'actor-xarxa, traducció, actant, mediació.

\section{Abstract. The sociothecnical approach in policy analysis}

This article explores the ways in which recently appeared concepts, tools and analytical approaches from actor-network theory (ANT) invites an alternative account of policy analysis.

Key words: policy analysis, actor-network theory, translation, actant, mediation.

\section{Sumari}

Introducció Què ocorre en les xarxes?

La teoria de l'actor-xarxa Com hem d'entendre les accions?

i l'assemblatge social

La perspectiva de la traducció

Lactor-xarxa heterogeni

Referències bibliogràfiques

Què en fem del context? 


\section{Introducció}

Aquest article vol oferir una reflexió que contribueixi a identificar millor la composició i les dinàmiques que tenen lloc en els processos de producció de polítiques públiques (Aguilar, 1996; Brugué i Gomà, 1998; Subirats, Knoepfel, Larrue i Varonne, 2006), és a dir, en els entramats de decisions i accions portades a terme per una gran diversitat d'actors que, a través de la utilització de determinats recursos i en el marc d'unes institucions que reglamenten les seves accions, participen en la solució d'un problema col-lectiu. En el transcurs d'aquestes pàgines, tractarem sobre l'interès per l'anàlisi de polítiques públiques (Brugué, Gomà i Subirats, 2005; Gomà i Subirats, 1998) dels diversos conceptes o instruments i plantejaments analítics que han aparegut, en els darrers anys, en la literatura al voltant de la teoria de l'actor-xarxa (ANT), una aproximació provinent dels estudis socials de la ciència i la tecnologia i que ha destacat per mostrar la interessant articulació de xarxes sociotècniques per part dels científics. Així, en el primer apartat, hi trobem una introducció a la teoria de l'actor-xarxa i un repàs de les aportacions teòriques principals. En destaca la crítica als plantejaments convencionals que mantenen una estricta separació entre el que és social i el que és natural, limitant el tipus d'agregats i d'agències i excloent-ne la major part d'elements no humans. Allò social s'acostuma a concebre com «alguna cosa oculta darrere nostre», però, des de la perspectiva exposada en aquest apartat, no considerem que estigui «ocult», sinó que simplement és "desconegut», i no està «darrere», ni tampoc «sobre» els nostres caps o «abans» de les accions, està «enmig», $\mathrm{i}$ «després» de l'acció, per «sota» dels participants i actuant en el "primer pla» (Latour, 2005).

Tot seguit, en el segon apartat, s'hi reflexiona sobre la naturalesa heterogènia de la societat i el paper dels objectes en els processos de producció de polítiques públiques $\mathrm{i}$, en general, en el manteniment de l'ordre social, i s'hi proposa una concepció alternativa per a les xarxes de polítiques públiques: l'actor-xarxa.

El tercer apartat és força breu i s'hi planteja la necessitat d'abandonar la dicotomia formada pels conceptes local i global i de dissoldre la definició de context, en tant que constitueix quelcom extern, fet de forces socials i que determina el que és "a dins», i adoptar una perspectiva que els comprengui com quelcom recollit, resumit i planejat en espais determinats. En el quart, d'altra banda, s'hi proposen plantejaments crítics i alternatius, tant per a la definició convencional de causa com per al tractament del «vehicle» (Latour, 2005) que se suposa que transporta els efectes, i s'hi planteja una manera de comprendre l'agència i les accions, en tant que mediació i resultant d'una heterogeneïtat d'elements.

Finalment, el darrer apartat, la darrera reflexió, és l'exposició de la perspectiva de la traducció o de les associacions, que permet fer l'anàlisi de l'articulació de l'actor-xarxa i les interaccions entre els seus elements. Per tant, és molt interessant per abordar les diverses dinàmiques que es donen en els processos de producció de polítiques públiques. 
Abans de començar, però, cal destacar que tot el que exposem o sobre el qual reflexionem en aquestes pàgines no només té a veure amb la proposta d'un mètode o de determinats recursos o perspectives que poden esdevenir útils per realitzar l'anàlisi de polítiques públiques. Fa referència, també, al tipus de realitats que volem reconèixer $\mathrm{i}$ al tipus de món que volem considerar, com també a una manera d'estar, de posicionar-se, tant analíticament com políticament.

\section{La teoria de l'actor-xarxa i l'assemblatge social}

La teoria de l'actor-xarxa (ANT) (Latour, 2005; Domènech i Tirado, 1998) és una de les aproximacions més destacades de les que provenen dels estudis socials de la ciència i la tecnologia (ESCT), i es caracteritza per haver radicalitzat el principi de simetria (Vitores, 2001) proposats pel programa Fort (Bloor, 1998) en sociologia. Aplicada als estudis sobre la producció científica o tecnològica, ens ha aportat la perspectiva de l'enginyeria heterogènia, la pràctica de construcció per part dels científics de xarxes sociotècniques, és a dir, xarxes que no només combinen elements humans.

És en aquest sentit que Law i Mol (1993) afirmen que, per construir un cotxe elèctric, cal construir, també, una societat apta per tal que aquest hi pugui viure. Han d'aparèixer nous tipus d'acumuladors i bateries, s'han d'organitzar laboratoris amb científics, determinades empreses rivals s'han d'escindir i reorganitzar per fabricar les carrosseries necessàries, cal convèncer els ajuntaments perquè incentivin el transport públic elèctric i els usuaris perquè considerin que els vehicles elèctrics són un mitjà pràctic, etc. Així, el cotxe elèctric, expliquen, s'ha de considerar un conjunt de relacions entre electrons, bateries, laboratoris, ajuntaments o consumidors, que, al mateix temps, també són conjunts d'efectes relacionals, que, en cap cas, es pot afirmar que existeixin per si mateixos; al contrari, són relacions o conjunts de relacions entre relacions constituïts en les xarxes de les quals formen part, i no existeixen més enllà de les seves interaccions.

Segons l'ANT, aplicada en múltiples ESCT, l'èxit d'un projecte (tecnològic o científic) depèn de la seva capacitat de simplificar un àmbit determinat de la realitat, per, llavors, estructurar i associar tot un seguit d'elements heterogenis al llarg del temps. El resultat d'aquest procés — primer- de traducció o simplificació de la realitat i — després — d'enrolament o associació de diverses entitats vinculades entre si durant un període determinat, és el que anomenen l'actor-xarxa, quasi objectes o quasi subjectes formats no només per entitats socials, sinó també per entitats no humanes, i que estan en dinamisme constant, renovació dels seus components i vincles, i transformació de la seva identitat.

En el marc d'aquesta interessant producció d'ESCT, la teoria de l'actorxarxa també ha qüestionat la dicotomia formada per societat i tecnologia, argumentant que la frontera que hi ha entre els dos conceptes és borrosa. Des de l'ANT, quan es parla de fet social, es fa referència a quelcom format tant per elements tècnics com socials, és dir, a quelcom que no és pur, sinó heterogeni. 
I els seus estudis ens han mostrat tots els artefactes implicats en les relacions humanes, en la nostra realitat. Una realitat que es configuraria a través de xarxes dinàmiques que, en dependre de la força amb la qual s'associen els seus elements, tracten de créixer o d'enfortir-se per poder competir amb altres xarxes. I on els materials estan imbricats amb els humans de maneres diverses, ja que cadascuna de les opcions o estratègies de relació, que són formes d'acció i organització, al mateix temps, són formes diferents de traçar i de tornar a traçar la frontera entre la humanitat $\mathrm{i}$ les màquines, que en cap cas està fixada de forma unívoca.

L'ANT ens ha aportat el reconeixement que els elements no humans, amb els quals interactuem i intercanviem propietats, tenen un destacat paper en la definició i el manteniment de les nostres societats i de les nostres relacions socials, que són també actors, i no simples portadors de significat. En aquest sentit, diversos autors provinents de l'ANT han lamentat que la majoria de plantejaments analítics s'hagin limitat a entendre la naturalesa del llaç social en termes estrictament humans (Rodríguez, Tirado i Domènech, 2001), i han proposat explicar allò social deixant de banda la preocupació exclusiva per les relacions socials i prenent en consideració els actants no humans, així com els procediments tècnics en què estan involucrats. És sobre aquestes qüestions que reflexionarem tot seguit, plantejant que el que ens manté units no és un contracte social abstracte o un llaç polític racional i perfectament organitzat, sinó l'elaboració permanent i precària de compromisos entre humans i no humans (Domènech i Tirado, 2008a).

Des de la teoria de l'actor-xarxa, s'ha reflexionat en diverses ocasions sobre el fet que les perspectives analítiques convencionals considerin que existeix un context social en el qual participen unes altres activitats no socials; un domini concret de la realitat, una mena de força social que ens permet explicar determinats aspectes residuals que a uns altres dominis, com ara la psicologia, el dret o l'economia, se'ls escaparien (Latour, 2005). Aquesta posició, hi afegeix el mateix autor, ha esdevingut comú per a la majoria dels científics socials, però també forma part del sentit comú d'altres actors, com ara periodistes, polítics, professors o contertulians de bar. Així, l'adjectiu social s'acostuma a emprar per referir-se a dos tipus de situacions diferents: a casos de situacions d'interaccions locals, properes, que podríem anomenar cara-a-cara i, també, per fer referència a una mena de força misteriosa que ens permet justificar que allò que passa en les situacions del primer tipus, les properes, també ocorre en la distància, tant temporal com en l'espai.

En aquest sentit, és especialment Bruno Latour (2005) qui ha plantejat més i millor tot aquest plegat de qüestions i ha proposat unes ciències socials que deixin de ser la «ciència del que és social» $\mathrm{i}$ es fixin en les associacions que es van traçant al nostre voltant. Així, des d'aquest plantejament, «social» ja no es referiria a una cosa enmig d'altres, com una ovella negra entre unes ovelles blanques, sinó a un tipus de connexió entre coses que no són, elles mateixes, estrictament socials. Aquest autor no defineix el que és social com un domini especial, un reialme especial o un tipus concret de coses, sinó com un movi- 
ment molt peculiar de reassociació, reacoblament, reassemblatge, l'estudi dels quals anomena sociologia de les associacions o associalogia (joc de paraules entre els termes sociologia i associacions). I és que allò social, hi afegeix, es troba en els sorprenents moviments entre una associació $\mathrm{i}$ una altra, $\mathrm{i}$ davant d'aquesta realitat, en el marc d'un anàlisi, hi ha dues postures: es poden suspendre aquests moviments o es poden seguir. Quan es decideix suspendre'ls, com es fa habitualment, avisa, allò social és normalment construït remetent a una participants acceptats anomenats actors socials que són membres de la societat. Això no obstant, si, al contrari, optem per seguir aquests moviments, dibuixem allò social a través de les associacions, també, de diversos elements no socials, amb l'objectiu, diu, d'anar a parar a una definició compartida d'un món comú.

Segons els principals referents de l'ANT, aquesta creença en una mena de boira que ens envolta, i que anomenem societat o llaços socials, ha provocat que els plantejaments analítics renunciessin a una gran quantitat de detalls i de fonts d'informació, és a dir, el fet d'haver buscat sempre una resposta en termes de llaços socials ha estat una pega, una nosa, per al pensament occidental, que no ha considerat que els factors socials no siguin suficients per explicar les dinàmiques socials.

A partir de la perspectiva que tractem en aquestes pàgines, els elements que conformen allò social són d'una gran varietat. De fet, quan parlem d'allò social, ens referim a la relació que s'estableix entre un conjunt d'elements heterogenis en un moment determinat, ja siguin éssers humans, significats que produïm, símbols, discursos o elements materials com ara artefactes tècnics, objectes, etc. (Tirado i Domènech, 2005). Així, des d'aquesta perspectiva, la xarxa social és interpretada com una estructura composta d'actants — concepte per referir-se a qualsevol tipus d'element participant_ en interacció.

Segons l'ANT, els factors socials no són suficients per explicar tot allò que passa en la societat, per tant, cal fixar-se també en els factors no humans i en els procediments tècnics en què estan involucrats. I és que una de les aportacions de la teoria de l'actor-xarxa és la comprensió del fet que el sosteniment de les comunitats humanes, en un esforç constant per reduir la seva complexitat o sofisticació, ha depès i depèn d'elements que no són humans. Les comunitats humanes se sostenen gràcies a elements no humans, que tenen un paper preeminent en l'establiment d'associacions i la generació de col-lectius. De fet, des del punt de vista d'aquesta aproximació, els aparells, allò tecnològic, tindrien un paper decisiu en el procés de construir la societat a gran escala, garantint la seva permanència en el temps, és a dir, garantint l'estabilitat d'allò social.

Tot i que hi reflexionarem més endavant, la relació entre materialitat i socialitat permet fer la reflexió sobre unes altres maneres d'entendre les relacions de poder que poden ser interessants, també, per analitzar processos de producció de polítiques públiques. Miquel Domènech i Francisco Javier Tirado (2001) plantegen que les definicions que se solen fer del poder, comprès com una mena de força misteriosa, comparteixen una «zona fosca» en relació amb la manera com consideren que opera, de facto, i es manté en el temps i en l'espai. En canvi, la relació entre materialitat i socialitat permetria aclarir l'acció con- 
creta de l'exercici del poder i entendre com es pot exercir amb caràcter durador, en la distància i a través del temps. Els autors ens destaquen la necessitat que té el poder d'inscriure's en quelcom material per tal de subsistir en el temps i en l'espai. La inscripció són tots els tipus de transformacions a través de les quals una entitat es materialitza en un signe, un arxiu, un document, un tros de paper o un traç. Les inscripcions, explica Tirado (2001), es mouen generant noves articulacions, noves connexions i jocs de relacions en les quals s'impliquen tant subjectes com objectes de tot tipus, la qual cosa dóna com a resultat un element híbrid.

En aquestes pàgines, entendrem el poder, com hem fet amb la societat, no pas com un dipòsit, un recurs o un capital que ens assegura una explicació per a les nostres anàlisis, sinó com el resultat d'un procés en què intervé una gran heterogeneïtat d'elements. La producció d'ordre social, la seva fragilitat o consistència, depèn de quelcom tan senzill o complex com és la materialitat sobre la qual es basa un exercici de poder determinat (Domènech i Tirado, 2001).

En definitiva, per acabar aquest apartat, és tot aquest grapat de reflexions i arguments els que fan que, des de l'ANT, es rebutgi que el que ens manté junts és allò social, ja que, ans al contrari, es consideri com el que és sostingut i mantingut. Només és possible entendre el que ens manté units, ens proposa la perspectiva, si deixem de fixar-nos només en els elements socials i adoptem una perspectiva que incorpori actors/actants no humans, i que reconegui el seu paper en les nostres anàlisis de la realitat social. No hem d'entendre els artefactes com a coses, els hem d'allotjar en la nostra cultura intel.lectual en tant que actors socials de ple dret (Latour, 1998), fet que suposaria incorporar, en els nostres plantejaments analítics, els elements que ens ofereixen l'oportunitat de mantenir unida la societat com a totalitat duradora (Latour, 1991).

\section{L'actor-xarxa heterogeni}

Seguint el fil encetat en l'apartat anterior, bona part del estudis socials de la ciència i la tecnologia defensen la pertinença d'enfocaments que assumeixin una composició heterogènia de la realitat, qüestionant les tradicionals dicotomies de la modernitat que separen societat i tecnologia, ciència i tecnologia $o$ ciència i societat, $\mathrm{i}$ les distincions entre allò humà i allò no humà o entre objecte i subjecte (Domènech i Tirado, 2008b). En aquest apartat, hi desenvoluparem aquest argument amb el propòsit de reflexionar sobre l'interès d'una proposta de concepció heterogènia per a les xarxes en les anàlisis de la producció de polítiques públiques.

En el marc dels estudis socials de la ciència i la tecnologia, com expliquen Domènech i Tirado (2008a), la voluntat d'evitar distincions a priori entre diferents tipus d'entitats ha conduït a un interessant debat sobre la materialitat. El que s'ha anomenat postulat de l'heterogeneïtat convida a dissoldre les fronteres entre el domini social i el domini d'allò natural o tecnològic, de tal manera que les característiques que tradicionalment s'imputaven als humans apareixen, ara, relacionades amb elements no humans. Així, des d'aquest principi 
de simetria radical, com ja hem apuntat, no assignaríem cap qualitat inherent a cap entitat, sinó que la consideraríem una "producció o emergència» de xarxes heterogènies, d'entramats compostos per materials diversos.

Ara bé, en la majoria d'anàlisis, trobem una clara separació dels elements que participen en els processos estudiats basada en el criteri material. Ens tranquil.litza poder distingir facilment entre el que és humà i el que no, i tal i com destaquen Domènech i Tirado (2008a), una prova d'aquest fet és la inquietud que ens provoca qualsevol intent que suspengui aquesta diferenciació, com són els relats de terror, on apareixen personatges monstruosos que són, ni més ni menys, barreja del que no es pot barrejar. Cossos humans i caps animals, humans amb parts artificials, tot plegat, combinacions que qüestionen la nostra capacitat per catalogar allò material.

Aquests autors, però, van més enllà de les pàgines de literatura de terror i fan referència a un tipus d'entitat present a les ciències socials i que comparteix, amb els mencionats monstres dels contes de terror, la seva indefinició respecte a les tradicionals fronteres entre el que considerem humà i el que no, la qual anomenen cyborg. Entitats com el cyborg són imatges metaforiques que pretenen capturar i representar quelcom nou que emergeix en la nostra realitat quotidiana. Els cyborgs, destaquen Tirado i Gàlvez (2002), tenen dues característiques principals. La primera, l'heterogeneïtat, mostra com actors socials humans, objectes tecnològics, processos, idees, etc. conviuen en el mateix pla de realitat i acció, i amb el mateix estatus ontològic. Tot un seguit d'elements heterogenis que adquireixen sentit en relació amb els altres. La segona, la transgressió, fa referència a la ruptura d'antigues dicotomies com ara home/dona, $\mathrm{viu} / \mathrm{no}$ viu, humà/màquina, etc. Els cyborgs permeten captar unes realitats que, tot i ser quotidianes, mesclen plans i ruptures i ens ofereixen noves opcions d'identitat i noves formes d'interacció social. Són una entitat híbrida, fruit de l'assemblatge, la combinació i la interacció entre les possibilitats de la tecnologia i les potencialitats del que és humà o cultural. I ens recorden que les connexions entre nosaltres i les coses que ens envolten es donen a tot arreu, de qualsevol manera i en tot moment, explica Tirado (2001), i que aquestes connexions ens transformen sistemàticament, en un procés agònic sense principi ni final què tots traduïm i som traduïts.

Així, cal reflexionar sobre una concepció de la producció de polítiques públiques en tant que procés d'enginyeria heterogènia. I és que, de fet, en la línia del que hem exposat fins ara, tot el que ens envolta és heterogeni. John Law i Annemarie Mol (1993) ens conviden a pensar en aquesta heterogeneïtat en què vivim: la gent porta ulleres, pren medicaments, usa condons, despertadors, telèfons mòbils, carnets, i, al mateix temps, hi afegeixen, les màquines tenen pilots, usuaris, tècnics de servei, dissenyadors, espectadors, supervisors o explotadors. Segons els autors, la frontera entre éssers humans i objectes és difosa, i es tracta d'un efecte o un producte que podria canviar i, de fet, canvia constantment. En definitiva, el que ens exposen és la gran dificultat de demarcar nítidament i clara els éssers humans del que considerem, simplement, objectes. En aquest sentit, la visió sociotècnica aporta, a l'anàlisi de polí- 
tiques públiques, la possibilitat de captar un procés complex d'hibridació entre el que és humà i el que no ho és, representar una realitat híbrida que no és completament social, ni completament tècnica, sinó una mescla entre totes dues (Tirado i Gàlvez, 2002), reconeixent el fet que la frontera entre les quals és impossible de fixar.

La proposta és endinsar-nos entre l'heterogeneïtat i la discontinuïtat de protagonistes. Analitzar la interacció entre els elements d'aquest escenari heterogeni, sense necessitat de distingir entre "gent per un costat i coses per l'altre», sinó en tant que un conjunt d'elements que conformen una mateixa xarxa, un actor-xarxa, que, com qualsevol altra xarxa, es compon de molts elements diferents, i en tant que actor, incorpora activitat i acció (Domènech i Tirado, 2008a). És una proposta per a uns plantejaments analítics més oberts en referència a les formes i a la composició que poden prendre els actors a seguir en les nostres anàlisis. Perquè no hi ha cap grup rellevant que es pugui considerar que forma agregats socials, cap component estable s'ha de considerar, de manera inqüestionable i apriorística, com un punt de partida en les nostres anàlisis. És imprescindible que els analistes no definim, abans de començar i en lloc dels protagonistes, de quin tipus de construccions està format el nostre món social. La teoria de l'actor-xarxa, en aquest sentit, assumeix un principi semiòtic segons el qual qualsevol cosa que modifiqui l'estat de quelcom, induint alguna diferència, és considerat un actor $\mathrm{o}$, si no disposa de figuració concreta: un actant (Tirado, 2005).

Plantegem un tractament de realitat heterogènia, coherent $\mathrm{i}$ conscient per als processos de polítiques públiques que estudiem, perquè la majoria d'anàlisis no van més enllà del que tradicionalment ha constituït la matèria d'allò social, és dir, relacions entre humans o de poder, valors, processos cognitius o significats (Rodríguez, Tirado i Domènech, 2001). L'heterogeneïtat proposada fins avui no té en compte cap tipus de referència al paper «heurístic i explicatiu» que poden tenir els elements no humans, quelcom imprescindible per a una anàlisi completa dels processos de polítiques públiques, que es caracteritzen per dependre d'articulacions entre elements heterogenis, desplegades en una heterogeneïtat en la qual humans i no humans comparteixen un mateix entramat d'acció i significat.

En aquest sentit, Tanja A. Börzel (1998) assenyala que la principal distinció entre les diferents concepcions sobre les xarxes de polítiques públiques és en funció de si són homogènies o heterogènies. Segons l'autora, la majoria d'estudis sobre polítiques públiques es troben amb xarxes heterogènies, això no obstant, la seva heterogeneïtat no va més enllà de contemplar que els actors que hi participen tenen diferents tipus d'interessos i diferents tipus de recursos. Una xarxa de polítiques públiques, explica, inclou tots els actors involucrats en la formulació i la implementació de la política, això no obstant, concreta, inclou (només) tots els actors públics i privats. La resta de participants o són relegats a la categoria de recursos o són, simplement, ignorats.

Si partim, però, de la perspectiva d'aquestes pàgines, caldria fixar-se més en les dinàmiques en les quals intervé aquesta gran varietat d'elements que tan 
injustament han estat relegats a la categoria de recursos. Cal fixar-se en el seu paper, en el seu rol, en el seu protagonisme, cal reconèixer que, a més de connectors que permeten realitzar l'associació d'altres elements, ells mateixos són també una xarxa. Com veurem més endavant, constitueixen l'ingredient dels processos de traducció que configuren i donen forma a les xarxes. Són actors, actants, imprescindibles per comprendre la complexitat de les dinàmiques de qualsevol procés de producció d'una política pública.

Seguint el fil del que hem exposat en el transcurs d'aquest article, si deixem de banda el prejudici de considerar que allò que anomenem social només implica els humans i les seves relacions, se'ns presenta l'oportunitat d'articular plantejaments que concebin el món de les coses, naturals o tecnològiques, i el dels humans com una mateixa xarxa. Les xarxes sociotècniques són entramats complexos de relacions i associacions formats per entitats múltiples i heterogènies, és a dir, artefactes tecnològics, usuaris o actors virtuals, energies, fluxos d'informació i comunicació o materials, o elements polítics, socials, econòmics, tecnològics, culturals que actuen com un tot relacionat (Tirado $\mathrm{i}$ Gàlvez, 2002). L'actor-xarxa és un objecte híbrid, és alhora natural, social i discursiu. No té naturalesa intrínseca, sinó que la seva identitat és un producte resultant de les relacions que el conformen. És un acoblament d'elements heterogenis en el qual són més importants la força i el tipus d'associacions o relacions que la naturalesa dels seus components.

\section{Què en fem del context?}

Si no heu començat la lectura de l'article per aquest apartat, no us sorprendrà que, arribats en aquest punt, per a la proposta de reflexió en el marc de l'anàlisi de polítiques públiques que estem desenvolupant en aquestes pàgines, la definició convencional de context en les ciències socials se'ns presenti com a poc útil, ja que difícilment té en compte, inclou o incorpora el paper que hi tenen els no humans. No obstant això, l'anàlisi de xarxes de polítiques públiques atorga molta importància al context polític, social i institucional en el qual es porta a terme el procés (Kickert, Klijn i Koppenjan, 1998), i l'estudi del seu paper en el marc de processos de producció d'una política pública és quelcom comú, concretament, per valorar en quina mesura els afavoreix o els dificulta.

Així, a partir de les perspectives habituals, la majoria d'anàlisis s'han vist forçats a viatjar constantment entre (només) dos tipus de llocs molt diferenciats: les interaccions locals i el context global. No obstant això, en les pàgines d'aquest breu apartat proposarem renunciar a aquesta separació entre elements globals i elements locals, ja que partirem de la consideració, com explicarem tot seguit, que cap lloc domina suficientment per ser global ni cap és prou autosuficient per ser local. La societat no és el suficientment estable per no inscriure's en res, és impossible de mantenir sense reclutar no humans socialitzats. La societat està construïda, però com matisa Latour (1998), i no és el primer cop en aquest article, no pas (o només, hi afegim els autors) socialment 
construïda. La literatura ANT ens mostra el fet que qualsevol interacció local i en el present està subvertida per una quantitat espectacular de no humans, cadascun dels quals amb les seves disjuncions respectives. Així, per definir qualsevol element, hem de tenir presents dues qüestions (Tirado i Domènech, 2005): les altres entitats amb les quals es relaciona i el tipus de llaços que posseeix amb aquestes entitats, que poden estar basats en acords, desacords, negociacions, ruptures potencials, etc.

A partir de l'ANT, assumim que una acció, un episodi o un esdeveniment social ocorregut en el passat o en algun context llunyà, per tant, realitzat per autors absents, segueix present si es pot traslladar, traduir, inscriure, delegar o desplaçar en altres actants, precisament, no humans, que permeten un establir ordre social més o menys durador i que s'intercanviïn les propietats entre els nivells micro i macro de la interacció social (Tirado i Domènech, 2005). Tal com ens explica Latour (2005), el que està actuant en un determinat lloc i moment prové de diversos altres llocs, materials distants i actors remots, és a dir, en qualsevol interacció podem observar com hi participen, també, elements situats en un altre temps, d'un altre lloc i generats per un altra agència. Una eina, per exemple, és el resultat de l'extensió d'habilitats socials a no humans (Latour, 1998); l'acció tècnica és una forma de delegació que ens permet mobilitzar, durant les interaccions, moviments fets en el passat, en algun altre lloc i, fins i tot, per uns altres actants.

Cal tenir en compte, però, que cap acció és mai sincrònica, els elements que la formen són heterogenis i mai no actuen amb la mateixa intensitat $\mathrm{i}$, a més, són pocs els que es mostren visibles en un moment determinat. En la majoria de situacions, per tant, l'acció estarà interferida per una varietat aclaparadora d'elements, heterogenis, que no tindran la mateixa presència local, no provindran del mateix temps, no seran visibles immediatament i no empenyeran amb la mateixa força. Les interaccions locals, hem de considerar, són artefactes construïts en un complex joc de pràctiques i de relacions culturals $i$ materials; situacions que sempre ens condueixen a unes altres interaccions locals, a uns altres llocs, espais o agències; cal seguir aquests moviments, ens recomana l'ANT, per observar com progressivament es va conformant aquesta cadena, aquest plec d'actors (Tirado, 2005). Així, una anàlisi de polítiques públiques conscient d'aquesta naturalesa de les accions — deslocalitzades, articulades, delegades i desplaçades (Latour, 2005) — se n'hauria d'allunyar en direcció cap a unes altres localitzacions, unes altres èpoques i unes altres agències que li donin sentit; llocs, però, que no són pas allò que convencionalment hem entès com el seu context, aquesta mena de marc de referència o estructura en la qual se suposa que les accions estudiades haurien «niat».

Els contextos, des de la perspectiva d'aquestes pàgines, s'han de considerar recollits, resumits i planejats en espais determinats des d'on incorporen els seus diversos i contradictoris efectes estructurals als llocs que contextualitzen o estructuren. La dimensió macro no està ni «per sobre» ni «per sota» de les interaccions, sinó afegida a elles, en tant que una altra connexió, alimentant-se'n i alimentant-les (Latour, 2005). 
En les nostres aproximacions, per tant, traçarem un actor-xarxa si prenem la decisió de substituir determinats elements per llocs locals i connectats, i no pas en classificar-los en funció de si formen part de la dimensió micro o la macro. Aquesta és una qüestió que incumbeix els actors estudiats. Un cop la concepció de societat global desapareix, la plena gamma del que circula "a fora» es troba ara en el primer pla. Ni el context ni les interaccions locals han de ser el nostre punt de partida. La nostra atenció s'ha de centrar, en primer terme, en els connectors que permetran establir l'enllaç entre les interaccions i els seus contextos. Latour (2005) proposa «arrossegar-se» cap a molts llocs on allò global, allò estructural, allò total, és conjunt i on s'expandeix enfora gràcies a determinats cables o conductes.

Per tal de completar i deixar clara la proposta d'aquest apartat, ens aturarem a reflexionar sobre les bandes rugoses que ens podem trobar en moltes de les carreteres per les quals circulem. Un objecte del qual en podríem descriure un guió, format per totes aquestes relacions que "produeix» o permet, per les possibilitats que obre i per les disjuncions que suposa. La banda rugosa és un guió que reparteix propietats, entre humans i no humans, en funció d'efectes i possibilitats, i recull la voluntat i la delegació d'enginyers, legisladors, discursos morals, codis de circulació que es barregen amb la línia d'acció de la grava, la pintura, els càlculs estandarditzats i el formigó; porta actes pesats al present, prepara els futurs i permet que els seus creadors desapareguin, però es mantinguin presents (Tirado i Domènech, 2005).

Tant els objectes com els subjectes, són guions (Tirado i Domènech, 2005). S'hi estableix un marc d'acció juntament amb uns altres actors, com també l'espai i el temps en què se suposa que es donarà l'acció. El guió contempla les relacions i les constriccions que comporten uns altres actors. Cada objecte porta inscrit un món, és tot un món i descriu un món quan es desplaça. El guió estableix competències, responsabilitats i agència, en la mesura en què marca potencialitats futures. La noció de guió intenta cartografiar i recollir la trajectòria d'accions i relacions en les quals té un paper un determinat element. Una mena de currículum d'experiències i aptituds, de les seves associacions disponibles, de les seves propietats o conseqüències potencials. El guió és una espècie de forat negre que atrau les propietats de tots els elements, les barreja, les sintetitza, les materialitza i les converteix en una realitat puntual, concreta, discernible i perfectament situada (Tirado, 2001).

La banda rugosa recull certes potencialitats i efectes, aconseguint el que Latour (1998) anomena un efecte de desembragatge, una disjunció especial, temporal i actorial. I aquest és un exemple de disjunció actorial, perquè el formigó es transforma en policia; també de disjunció espacial, perquè ara la carretera on està instal.lada la banda rugosa està composta per un nou actant que fa disminuir la velocitat dels cotxes o, fins i tot, els espatlla, i, en tercer lloc, una disjunció temporal, perquè la banda rugosa hi és tant de dia com de nit.

Amb la disjunció, es produeix una identificació, una dinàmica en la qual els delegats es traslladen a uns altres marcs de referència. És a dir, una acció, realitzada fa temps per un actor ja desaparegut, segueix encara vigent, activa, aquí, 
entre nosaltres, en un món, el que ens envolta, ple de delegats tècnics (Latour, 1998). Per exemple, per comprovar aquest cas de disjunció actorial, o sigui, que la banda rugosa rebi propietats típicament humanes, que sigui capaç d'assumir característiques, fins avui, atribuïdes només als subjectes humans, ens podem fixar en el curiós nom que s'empra per referir-se a aquests objectes en països com ara França, Haití, Quebec, Bèlgica o Suïssa, concretament al cantó de Ginebra, on responen al nom de gendarme couché; o a Anglaterra, que ho fan al de sleeping policeman. Així, les bandes rugoses es coneixen, en determinats indrets d'aquests països, com a "policies estirats», "policies al llit», "policia dormint» "esquenes de policia» o, en el cas de Mèxic o Jamaica, com a «soldats al llit».

Com expliquen Tirado i Domènech (2005), amb l'exemple de les bandes rugoses, observem com una acció, portada a terme fa molt de temps, per uns actors absents $\mathrm{i}$ amb uns objectius o unes intencions determinats, segueix activa i generant efectes avui en nosaltres. I és que els objectes mobilitzen persones i terres remotes, disposats a convertir-se en gent o coses (Latour, 1998). I la banda rugosa ofereix un pont entre creadors i usuaris i és mediadora per tal que es perpetuïn unes conductes determinades. Fa d'actor, actuant, per exemple, en lloc de l'enginyer o del policia. A més, realitza, reprodueix, ofereix, una realitat material i accessible a normes, propòsits diversos, rutines o valors, $\mathrm{i}$ obre unes condicions determinades de possibilitat per a tot conductor potencial. Des d'aquesta perspectiva, en definitiva, la distinció entre context i contingut es torna inservible, ja que l'un i l'altre no són discernibles entre si. I permet concebre, en l'anàlisi de polítiques públiques, com un esdeveniment passat, llunyà $\mathrm{o} \mathrm{amb}$ protagonistes absents pot seguir present, si s'aconsegueix traduir-lo, desplaçar-lo, inscriure'l en uns altres elements, si pot ser, tan mòbils i duradors com sigui possible.

\section{Què ocorre en les xarxes? Com hem d'entendre les accions?}

En els apartats anteriors, hem reflexionat sobre la necessitat de reconèixer que la societat necessita elements no socials per formar-se i mantenir-se. Però reconèixer que hi ha connexió entre actors o, fins i tot, que les xarxes són heterogènies no és suficient. La qüestió sobre la qual tractaré en aquest apartat té relació amb la manera com s'entén l'efecte d'aquests elements no humans, perquè ser conseqüent amb les aportacions provinents de la teoria de l'actor-xarxa depèn, sobretot, de com permets que siguin i actuïn els teus actors, qüestió molt important a l'hora de plantejar qualsevol anàlisi, per exemple, d'un procés de producció d'una política pública.

A partir de les perspectives tradicionals, consideraríem que els propòsits i les intencionalitats no són propietats dels objectes. No obstant això, la teoria de l'actor-xarxa ens convida a considerar que tampoc no són propietat dels subjectes humans. No és necessari buscar causes o inputs per determinar com arriben determinats efectes o com es generen certes conseqüències o outputs. De fet, la proposta que s'hauria d'extreure d'aquestes pàgines seria no interessar-se tant 
en les intencions, que, d'altra banda, són complicades de discernir, i més en les relacions i els efectes d'aquestes.

D'altra banda, com explica Tirado (2001), el pensament social, fins ara, pressuposa que l'acció és una mena de "produir-ser», la conversió de quelcom potencial en quelcom actual, és a dir, generar un moviment del que és potencial al que és actual. Un exercici, per tant, amb un punt d'origen clar i que genera un moviment que transforma un determinat estat de les coses. En canvi, l'acció, des del punt de vista sociotècnic, apareix com la mediació de l'acció de l'altre, un exercici d'estar «entre», d'ocupar la posició «enmig»; l'acció és mediació, actuar és permetre la connexió d'altres elements o entitats.

El mateix autor proposa l'exemple del surfing, referint-se a la forma d'entrar en una onada existent i gestionar un moviment i una acció ja existents. Aquí, diu, no hi ha origen, només posada en òrbita, accés i ús del mitjà i de les seves possibilitats. A partir d'aquest plantejament, desapareixeria el reconeixement de la necessitat d'un subjecte propi per a l'acció, la presència, més o menys sobreentesa d'un objecte, la tensió entre competència i execució i la dualitat formada pels conceptes potencial i actual. Les accions són connexions, xarxes, entre materials diversos que generen efectes de reestructuració en els seus guions, establint noves ordenacions. I l'agència l'entenem com un èxit precari generat per una xarxa de materials heterogenis.

Segons Latour (2005), la diferència sobre el paper que atribuïm als no humans dels diversos plantejaments analítics rau a considerar-los intermediaris o mediadors. Un intermediari, defineix, és quelcom que transporta significat o forma sense transformar-ho. Així, coneixent-se els inputs, en podríem esbrinar els outputs. Segons la perspectiva que defensa l'autor, però, totes les entitats que participen en els processos que tenim la intenció de comprendre i analitzar, s'haurien de considerar mediadors, i no mers intermediaris.

De fet, la paraula clau per comprendre la forma d'entendre les accions que proposaré en aquest apartat és mediació, un concepte al qual Latour (1998) atribueix diversos sentits i que són la base de les propostes de reflexió que el lector o lectora trobarà en aquest apartat. El primer dels sentits de la mediació és la traducció, un concepte sobre el qual parlarem més endavant i que fa referència a la capacitat de generar nous actants i objectius en les associacions amb altres elements. Un desplaçament, una deriva, una invenció, la creació d'un llaç que no existia i que modifica els elements que lliga.

Latour (1998) utilitza l'exemple de l'ús de les armes per explicar aquest sentit. Segons ell, la persona enrola l'arma o és enrolada per ella - no importa qui enrola qui- $\mathrm{i}$ un tercer agent sorgeix a partir de la fusió dels altres dos, amb la creació d'una nova meta que no correspon a cap dels dos programes d'acció dels agents implicats. És a dir, no hi ha un desplaçament de l'element enrolat — sigui quin sigui- cap a l'objectiu de l'altre, sinó un desplaçament conjunt, amb l'aparició d'un nou programa d'acció per al nou agent esdevingut fruit del procés de traducció. Així, segons el mateix autor, ets una persona diferent amb l'arma a les mans, i l'arma és diferent amb tu sostenint-la; és un error partir d'essències, l'essència és l'existència i l'existència és acció. 
D’altra banda, el segon sentit del concepte de mediació és la composició, i fa referència al fet que l'acció no és simplement una propietat dels humans, sinó de l'associació de diversos actants que s'ajunten en el marc de processos en què es produeixen intercanvis de competències i s'ofereixen, els uns als altres, noves possibilitats, objectius i funcions (Latour, 1998). El tercer és la reversibilitat del plantejament en forma de caixa negra, és a dir, la capacitat de fer tornar opaques les relacions entre elements. Finalment, el darrer dels significats és la delegació, és a dir, el procés pel qual les tècniques modifiquen el contingut, i no només la forma, del que expressem, ja que tenen, també, significat.

En aquestes pàgines, hi plantegem una concepció de l'acció que no contempla els no humans com a simples recursos o constrenyiments per als humans, sinó en tant que associació, que, a través de processos de traducció — sobre els quals tractarem més endavant-, configura construccions híbrides entre humans i no humans que van ordenant, organitzant $i$, en definitiva, configurant el món en què vivim. Una acció, a més, que es presenta sempre imprevisible, ja que és un efecte relacional d'un col-lectiu híbrid i no es pot entendre de forma reduccionista com a conseqüència de la intenció prèvia d'un actor determinat (Domènech i Tirado, 2008a). Així, el motor principal d'una acció és un conjunt de pràctiques, distribuïdes i arrelades, la suma de les quals podria realitzarse, només, si respectéssim el paper mediador de tots els actants mobilitzats en la llista (Latour, 1998).

I és que els objectes no disposen d'un paper rellevant en les nostres anàlisis, no només a causa de les definicions del que és social de les perspectives convencionals, sinó també per les definicions més habituals dels conceptes d'actor i agència (Latour, 2005). Habitualment, es considera que la diferència entre humans i no humans és que els primers tenen la capacitat d'actuar per si sols, és a dir, estan dotats d'agència, i els segons, no. La proposta d'aquestes pàgines és que tothom qui generi un efecte de relació o tingui algun valor de significació s'ha de considerar un agent. Agents que, en les xarxes, estan constantment apareixent, movent-se, desapareixent, intercanviant el seu lloc amb altres, produint una relació, entrant en un joc de relacions nou, sortint d'un de vell, i així successivament (Tirado, 2001).

Tornem a parlar d'armes i fixem-nos en el debat que es basa en la pregunta: qui mata, les armes o les persones? Tal com expliquen Domènech i Tirado (2008a), aquest debat s'acostuma a limitar a dues postures possibles. La primera, anomenada realista, considera que les tecnologies no serveixen per a qualsevol cosa i, per tant, les armes són per matar. D’altra banda, la construccionista qüestiona l'autonomia de les armes i és partidària de fixar-se en els factors socials que n'expliquen l'ús. No obstant això, es pot optar, també, per considerar que l'ús de les armes és tant un procés social com tecnològic i, per tant, el culpable, si ens cenyim a la pregunta, no seria ni la pistola, ni la persona, sinó una mena d'entitat que podríem anomenar ciutadà pistola o pistola ciutadà. I és que a ningú no se li escapa que les persones canvien amb una pistola a la mà, de la mateixa manera que les pistoles són diferents si una persona les 
sosté. L'error en els dos plantejaments clàssics exposats, segons els autors, és partir d'essències, o dels subjectes o dels objectes.

Com explica Latour (1998), si és cert que un objecte tecnològic ha d'estar en mans d'un humà, és a dir, d'un agent que pugui concebre propòsits i que els engegui, cal reconèixer, també, que de cap manera els humans poden existir sense la necessitat d'entrar en relació amb allò que els «autoritza a existir» i els permet fer-ho, és a dir, els capacita a actuar. De la mateixa manera que, com també ja hem apuntat, pot ser cert que l'acció propositiva i la intencionalitat no siguin propietats dels objectes, no ho és tampoc dels humans. I això no vol dir estendre subjectivitats, ni confondre entre uns i altres, ni començar a tractar les coses com a humanes i a l'inrevés, sinó superar la clàssica distinció entre el subjecte o l'objecte, per passar a parlar d'un plec de implica mútuament humans i no humans. Així, el postulat de l'heterogeneïtat ens permet concebre noves formes de pensar l'acció humana i a l'agència, com a resultat d'entramats materialment híbrids (Domènech i Tirado, 2008a).

En definitiva, una de les aportacions principals a l'anàlisi de polítiques públiques d'aquest apartat és que unes altres agències, les quals no controlem, ens fan fer coses. I que hi ha moltes maneres d'aconseguir que algú faci coses, una gran diversitat de formes que, en les nostres anàlisis, no podem renunciar a desplegar limitant, des del principi, quines són les agències «reals» i quines són «falses». La coagència implica considerar que tots els elements d'un híbrid, i tot el conjunt d'entitats amb les quals està relacionat, participen i contribueixen en la seva agència.

En els nostres plantejaments analítics, com afirma Tirado (2001), davant d'aquest joc de relacions i de guions interactuant i autodeterminant-se no necessitem diferenciar el «com» i el "per què»; si despleguem aquest joc de relacions entre actants a través de totes les trajectòries en què participen, no cal buscar causes addicionals alienes o exteriors a tal desplegament. La tasca de l'analista és mostrar un conjunt d'actors o actants que afecten uns altres (Tirado, 2005) $\mathrm{i}$ incorporar la seva gran xarxa d'afectes que el fan actuar (Latour, 2005).

\section{La perspectiva de la traducció}

La perspectiva de la traducció és un dels elements més útils dels que provenen de l'ANT per realitzar l'anàlisi de les dinàmiques que es donen en els processos de producció de polítiques públiques. El concepte de traducció, però, no té una definició única. Per alguns autors, és quelcom molt concret. Per d'altres, conté tot - i encara més coses- el que hem exposat en aquestes pàgines. N'hi ha alguns que empren uns altres conceptes, com ara interessament o enrolament, per referir-se a qüestions molt semblants. Diversos autors vinculats a la teoria de l'actor-xarxa fan referència a la sociologia de la traducció, una sociologia de totes les negociacions, intrigues, càlculs, actes de persuasió i violència, gràcies als quals, un actor o força pren o se li confereix autoritat per parlar o actuar en nom d'un altre actor o força (Latour, 1991). Ens situem el marc d'una controvèrsia determinada, on els diversos actors desenvolupen argu- 
ments i punts de vista contradictoris que els porten a proposar diferents versions del món social i natural (Callon, 1986). A través dels processos de traducció, explica Law (1998), els diversos actors es disputen la imposició de la seva visió sobre la realitat, el nombre d'actors que en formen part, les seves característiques, la mida, a més de la naturalesa de les seves interrelacions i la posició de cadascú en relació amb l'actor que porta a terme la traducció, que té com a objectiu esdevenir un punt de pas obligat per a la resta. El procés de traducció implica l'atribució d'objectius i la fixació d'impossibilitats, en paral.lel al desplaçament d'un programa d'acció a un altre programa d'acció. Una traducció amb èxit, per tant, implica la capacitat per seleccionar o crear, caracteritzar o juxtaposar elements en una xarxa que té, com a mínim, un mínim de durabilitat.

Segons Latour (1998), traducció significa 'desplaçament, deriva, invenció, mediació, la creació d'un llaç que no existia abans i que, fins a cert punt, modifica els elements o els agents. Traduir és proposar o convèncer sobre una manera d'organitzar-se o entendre una qüestió determinada. Analitzar els processos de traducció ens permet descriure i entendre com s'ha arribat a un «ordre» de coses determinat. Com explica Callon (1986), en el procés de traducció es negocia la identitat dels actors, les seves possibilitats d'acció i els seus marges de maniobra, però no importa que el mecanisme de captura sigui constructiu; ni l'argument, convincent, l'èxit mai no està assegurat. Aquest rau a manipular, simultàniament i amb habilitat, factors socials i elements tècnics, és a dir, es basa en la capacitat d'associar entitats heterogènies entre si per tal de produir totalitats amb sentit (Domènech i Tirado, 2008a).

Callon (1986), en el mateix sentit del concepte de traducció, fa referència als «mecanismes d'interessament», és a dir, la manera com es poden mantenir els aliats en el seu lloc, el conjunt d'accions mitjançant les quals una entitat intenta imposar i estabilitzar la identitat dels altres actors que defineix a través de la problematització. L'autor empra aquest terme argumentant que «interessar» significa ser al mig, estar interposat, $\mathrm{i}$ en el marc d'un procés que comença amb la problematització, i segueix amb l'interessament, l'allistament, la mobilització i la dissidència. Segons l'autor, cada entitat enrolada per la problematització pot accedir a integrar-se en el pla inicial o, al contrari, optar per no fer concessions i definir les seva identitat, les metes, les orientacions, els projectes, les motivacions o els interessos d'una altra manera; en cap cas, però, destaca l'autor, de manera independent.

Anomena problematització els moviments i els desviaments que és necessari acceptar i les aliances que cal establir. Un procés, però, que no és pas ni una reducció ni una formulació simple de la qüestió o del conflicte, sinó una proposta d'enllaç, de combinació, que connecta elements, almenys parcialment o localment, de les seves diverses dimensions. L'interessament, com la traducció, es basa en una interpretació sobre el que són i el que volen els actors que s'intenta enrolar, així com també sobre les entitats amb què estan associats, $\mathrm{i}$ en intentar interrompre totes les associacions potencials amb les quals competeix per edificar un sistema d'aliances (Callon, 1986). 
La pràctica de l'enrolament fa referència al procés en el qual és proposat un ordre provisional (Grau, 2007). Descriure l'enrolament és, per tant, descriure el conjunt de negociacions multilaterals, judicis de força i trampes que acompanyen els mecanismes d'interessament i permeten que tinguin èxit (Callon, 1986). Aquest és, de fet, el procés a partir del qual es construeixen i es consoliden estructures socials formades per elements heterogenis.

Tornant al concepte de traducció, de forma coherent amb el que hem exposat més amunt, no ens interessen ni la causa ni el perquè de les nostres accions, sinó el com, en les pràctiques quotidianes, anem organitzant, ordenant, configurant i donant forma al nostre entorn, mitjançant associacions, entre elements heterogenis, a través dels mencionats processos de traducció. I el ventall d'estratègies o possibilitats és il.limitat. Pot ser la pura i simple força, la seducció, les concessions o una simple sol.licitud, un consens sense discussió, per exemple, en el cas que $B$ ja fos pròxim a la problematització de A. I exceptuant els poc habituals casos en què $\mathrm{B}$ coincideixi exactament amb la proposta, la identitat i la "geometria» de les entitats interessades es modificarà en el transcurs del procés d'interessament. (Callon, 1986). Una (només una) de les múltiples formes a través de les quals es donen els processos de traducció, i sobre la qual tractaré tot seguit, és a través de la categoria d'interessos, o sigui, intentant persuadir en relació amb els interessos dels altres, és a dir, provant d'imposar un ordre (propi) determinat en el món social.

Sobre la qüestió dels interessos, Börzel (1998) afirma que comprendre l'acció col-lectiva només és possible si aquests i les preferències no s'entenen com a donades o fixes. En aquest sentit, Callon i Law (1998) critiquen el que anomenen simplificacions reduccionistes d'un món social complex, que atribueixen interessos relativament estables a uns altres actors, al mateix temps que ignoren complexitats interminables en relació amb els seus motius, pretensions o accions com si pràcticament no tinguessin importància. Segons Law (1998), aquest plantejament es basa en la creença que el científic social disposa d'una explicació dels interessos socials més autoritzada que la dels que ell o ella estudia. Davant d'aquesta perspectiva, això no obstant, en podem tenir en compte una altra que suggereixi que els interessos, com també uns altres fenòmens socials, no són quelcom estable, sinó que estan reflexivament relacionats amb les concepcions que els actors tenen dels seus i dels de la resta d'actors amb els quals interactuen. A més, els interessos són negociables i, precisament, l'explicació dels seus orígens ha de ser l'objectiu del científic social. És a dir, la tasca passa a ser la de descobrir els mètodes pels quals els actors i les col-lectivitats articulen concepcions sobre la realitat que ens envolta, i les intenten imposar a uns altres.

Concretament, els teòrics de l'actor-xarxa es fixen en la manipulació i en la transformació d'interessos, ja que contemplen tot interès social com el resultat, temporalment establert, d'uns processos previs d'enrolament. I és que la teoria de l'enrolament, com hem dit, s'ocupa de les formes en què un ordre provisional és proposat $i$, a vegades, aconseguit (Callon i Law, 1998). I tot i que, fer-ho a través de la categoria dels interessos, com també hem dit, és una, 
i només una, de les possibles maneres d'aconseguir aquest enrolament, això no obstant, la transformació d'interessos és, tot i no ser l'únic possible, un intent per definir o reforçar les institucions, els grups o les organitzacions que ens envolten, és a dir, d'imposar ordre en una part del món social. Per traducció, podem entendre, també, la interpretació que els constructors de fets fan de llurs interessos i dels interessos de la gent que recluten (Latour, 1998).

La negociació entre els elements d'un actor-xarxa, la traducció d'interessos, segons Latour (1998), es pot dividir en cinc modalitats. La primera és adaptar els propis objectius als dels altres, o sigui, deixar-se reclutar. És una forma senzilla, però assegura poques garanties sobre el «respecte» de les aportacions pròpies. La segona implica convèncer els altres perquè et segueixin, $o$ sigui, que s'adaptin als teus interessos. La tercera consisteix a aconseguir un rodeig dels objectius, en convèncer els altres que, si segueixen els teus objectius, podran arribar abans a la consecució dels seus propis objectius o que, en cas d'obstrucció del seu camí, entenguin el teu camí com una drecera. Pel que respecta a la quarta, aquesta suposaria l'èxit del procés traductor, i és que significa aconseguir convertir-se en imprescindible, o sigui, un punt de pas obligat. La darrera estratègia és optar per a una reorganització dels interessos i els objectius, i es proposen cinc tàctiques per tal d'aconseguir-ho.

La primera de les cinc tàctiques consistiria a mobilitzar progressivament els objectius i els interessos del grup que es pretén enrolar, per tal d'incorporarlo a la teva xarxa. La segona tàctica proposada és inventar-se objectius nous, fites noves. La tercera seria inventar grups nous que serien dotats d'objectius nous. Pel que respecta a la quarta, aquesta es basaria a desviar progressivament el camí d'un grup sense que aquest se n'adonés. La darrera tàctica suposa intentar guanyar els judicis d'atribució, és a dir, emportar-se el mèrit sobre una associació o una consecució determinada.

Interessos i estratègies a banda, però, la raó de tota traducció és esdevenir un punt de pas obligat, aconseguir imposar als altres la teva perspectiva o convèncer-los que els problemes d'aquells només es podrien resoldre si passen a través teu. L’objectiu del procés de traducció és la dominació, quelcom, això no obstant, que no és un capital que es pugui emmagatzemar, cal que sigui desplegada, sobretot, intentant reduir el marge de negociació dels membres de la xarxa i transformar-los en caixes negres. Una xarxa romandrà en el temps no només gràcies a la durabilitat dels enllaços entre els punts, sinó també a causa del fet que cadascun d'aquests punts constitueix també una xarxa duradora i simplificada, que existeix només de manera contextualitzada, o sigui, en juxtaposició respecte a unes altres entitats a les quals està lligada (Callon, 1987).

La problematització inicial proposa una sèrie d'identitats, relacions i metes per als diferents elements, i al final del procés s'aconsegueix construir una xarxa de relacions constrictiva, però que es pot "denunciar» en qualsevol moment. Un actor pot fracassar al ordenar un ampli sector del món social en els termes de la seva simplificació o al redefinir els interessos dels altres actors. $\mathrm{O}$, de fet és el més habitual, es pot donar un triomf temporal, ja que la dominació no 
és un capital que pugui ser emmagatzemat en un banc, cal ser desplegat, reparat, mantingut (Latour, 1991). En cas de dissidència, es posa en qüestió algun dels fruits obtinguts en fases anteriors, es rebutgen o es desafien portaveus i desplaçaments, i apareixen noves veus, nous portaveus; els actors implicats no reconeixen els seus papers en la història (Callon, 1986) i es trenca la xarxa, per culpa de nous desplaçaments que desvien els elements dels punts de pas obligats que s'havien fixat. I és que el poder, com l'entenem en aquestes pàgines, és un efecte de conjunts d'embrollades i meritoses estratègies per enrolar els altres, i no pas com una causa d'aquest èxit.

La presentada en aquestes pàgines és, de fet, una concepció relacional del poder. Des de la perspectiva sociotècnica, la capacitat de determinats actors per controlar d'altres - tant se val que siguin éssers humans, institucions o entitats naturals_-, o per «obeir-los», depèn d'una complexa xarxa d'interaccions (Callon, 1986). L'actor capaç de forçar uns altres a moure's a través de canals particulars i d'obstruir l'accés a unes altres possibilitats és un actor que pot imposar-se sobre els altres (Law, 1998). No obstant això, la duració de la seva posició no ha de ser explicada pel seu poder, sinó per la convergència entre el que ell espera que els altres facin, i el que els altres esperen d'ell. Quan els actors són inestables, esdevé una situació negociable en la qual la dominació ja no s'exerceix. En canvi, quan s'alineen actors i punts de vista, obtenim una definició estable i una dinàmica de dominació.

A través del concepte de traducció, el poder el podem entendre com a efecte de la creació d'una xarxa formada per diversos elements en interacció constant, i la realitat social, com a producte d'aquests intents mutus de traducció. Amb l'aportació del concepte de traducció per part de l'ANT, el principal objectiu de l'analista hauria de ser descobrir els mètodes pels quals actors i col-lectivitats articulen concepcions sobre el món natural i social i intenten imposar-les a uns altres, fixant-se, també, en si triomfen o no en aquesta empresa. El resultat dels processos de traducció és una situació en la qual certes entitats en controlen unes altres i la seva anàlisi permet comprendre el que anomenem relacions de poder, o sigui, la manera com es defineixen els actors, com se'ls associa i, simultàniament, se'ls obliga a mantenir-se fidels a les aliances (Callon, 1986). A més, la perspectiva de la traducció permet descriure processos complexos en què es mesclen entitats heterogènies, $\mathrm{i}$ una explicació de com ben pocs obtenen el dret de representar i d'expressar-se en nom de molts que han estat «silenciats».

En definitiva, en el transcurs d'aquestes pàgines, a banda d'exposar la perspectiva de la traducció, hem reflexionat sobre noves maneres de plantejar i de comprendre el món social, les accions, l'agència, el poder, el context o el paper dels objectes, i hem destacat l'actor-xarxa com un instrument especialment pertinent per estudiar entitats heterogènies com són els actors i els processos de definició i implementació de polítiques públiques, ja que és un actor que interconnecta elements heterogenis $i$, al mateix temps, una xarxa que és capaç de redefinir i transformar allò de què està feta (Callon, 1987). Així, en l'anàlisi de polítiques públiques, si seguim la proposta de Latour (2005), i despleguem una xarxa socio- 
tècnica, definint trajectòries mitjançant l'associació i la substitució d'actants, definint actants a través de totes les trajectòries en les quals participa, seguint les traduccions i, finalment, també, variant el punt de vista dels observadors, no tenim necessitat de buscar cap causa addicional fora de les xarxes.

\section{Referències bibliogràfiques}

Aguilar, Luis (1996). La hechura de las políticas. México: Miguel Ángel Porrua. BLOOR, David (1998). Conocimiento e imaginario social. Barcelona: Gedisa.

BöRZEL, Tanja (1998). «Organizing Babylon: On the different conceptions of policy networks». Public Administration, núm. 76, p. 253-273.

BRUGUÉ, Quim; GOMÀ, Ricard (1998). Gobiernos locales y políticas públicas. Barcelona: Ariel.

BRUGUÉ, Quim; GOMÀ, Ricard; SubIRATS, Joan (2005). «Gobernar ciudades y territorios en la sociedad de redes». Revista del CLAD: Reforma y Democracia, núm. 32.

CALLON, Michel (1986). «Algunos elementos para una sociología de la traducción: la domesticación de las vieiras y los pescadores de la bahía de St. Brieuc». A: Juan M. Iranzo; Teresa GonZÁlez DE LA Fe i José R. Blanco (coords.). Sociología de la ciencia y la tecnología. Madrid: CIS, p. 259-282.

CALLON, Michel (1987). «El proceso de construcción de la sociedad. El estudio de la tecnología como herramienta para el análisis sociológico». A: Miquel DOMÈNECH i Francisco TIRADO (eds.) (1998). Sociología simétrica. Ensayos sobre ciencia, tecnología y sociedad. Barcelona: Gedisa, p. 143-170.

CALLON, Michel; LAW, John (1998). «De los intereses y su transformación: Enrolamiento y contraenrolamiento». A: Miquel DOMÈNECH i Francisco TIRADO (eds.) (1998). Sociología simétrica. Ensayos sobre ciencia, tecnología y sociedad. Barcelona: Gedisa, p. 51-62.

DOMĖNECH, Miquel; TiRADO, Francisco (1998). «Claves para la lectura de textos simétricos». A: Miquel DomèneCh i Francisco TIRADO (eds.) (1998). Sociología simétrica. Ensayos sobre ciencia, tecnología y sociedad. Barcelona: Gedisa, p. 13-50.

DOMÈNECH, Miquel; TiRADO, Francisco (2001). «Extituciones: Del poder y sus anatomías». Política y Sociedad, núm. 36, p. 183-196.

DOMÈNECH, Miquel; TIRADO, Francisco (2008a). El problema de la materialidad en los estudios de la ciencia y la tecnologia. Universitat Autònoma de Barcelona (en premsa).

DOMÈNECH, Miquel; TIRADO, Francisco (2008b). Cosmopolítica: agenda para una crítica del prejuicio de la especie. Universitat Autònoma de Barcelona (en premsa).

GomÀ, Ricard; Subirats, Joan (1998). Políticas públicas en España. Contenidos, redes de actores y niveles de gobierno. Barcelona: Ariel.

GraU, Marc (2007). «Ressenya de: Tirado, F. y Domènech, M. (2006). Lo Social y lo Virtual). Athenea Digital. Revista de pensamiento e investigación social, núm. 11 [en línia] <http://psicologiasocial.uab.es/athenea/index.php/atheneaDigital/ article/view/377/337> [Consulta: 23 de juliol de 2007]

KiCKerT, Walter J. M.; KLIJN, Erik-Hans; Koppenjan, Joop F. M. (eds.) (1998). Managing Complex Networks. Londres: Sage.

LATOUR, Bruno (1991). «La tecnología es la sociedad hecha para que dure». A: Miquel DOMÈNECH i Francisco TIRADO (eds.) (1998). Sociología simétrica. Ensayos sobre ciencia, tecnología y sociedad. Barcelona: Gedisa, p. 109-142. 
LATOUR, Bruno (1998). «De la mediación técnica». A: Miquel DOMÈNECH i Francisco TIRADO (eds.) (1998). Sociología simétrica. Ensayos sobre ciencia, tecnología y sociedad. Barcelona: Gedisa, p. 29-64.

LATOUR, Bruno (2005). Reassembling the social: an introduction to actor-network theory. Nova York: Oxford University Press.

LaW, John; Mol, Annemarie (1993). «Notas sobre el materialismo». Política y Sociedad, núm. 14-15, p. 47-58.

LAW, John (1998). «Del poder y sus tácticas. Un enfoque desde la sociología de la ciencia». A: Miquel DOMÈNECH i Francisco TIRADO (eds.) (1998). Sociología simétrica. Ensayos sobre ciencia, tecnología y sociedad. Barcelona: Gedisa, p. 63-107.

RodrígueZ, Israel; Tirado, Francisco; Domènech, Miquel (2001). «Los nuevos movimientos sociales: de la política a la cosmopolítica». Persona y Sociedad, vol. 25, núm. 3, desembre, p. 192-206.

Subirats, Joan; Knoepfel, Peter; Larrue, Corinne; Varonne, Frederic (2006). Análisis $y$ gestión de politicas públicas. Universitat Autònoma de Barcelona, versió mimeo (en premsa, Ariel, 2008).

TIRADO, Francisco (2001). Los objetos y el acontecimiento. Teoría de la socialidad mínima. Tesi doctoral. Universitat Autònoma de Barcelona. Bellaterra: Servei de Publicacions.

TIRADO, Francisco; GàlVEZ, Anna (2002). «Comunitats virtuals, ciborgs i xarxes sociotècniques: noves formes per a la interacció social». Digithum. Les humanitats en l'era digital, múm. 4 [en línia], <http://www.uoc.edu/humfil/articles/ cat/tiradogalvez0302/tiradogalvez0302.html> [Consulta: 23 de juliol de 2007]

TiRADO, Francisco (2005). "Reassembling the social: an introduction to actor-network theory. Recensió crítica». AIBR. Revista de Antropología Iberoamericana. Ed. Electrónica, Número especial (novembre-desembre) [en línia], <http://www.aibr.org/ antropologia/44nov/libros/nov0501.pdf> [Consulta: 23 de juliol de 2007]

TiRADO, Francisco; DOMĖNECH, Miquel (2005). «Asociaciones heterogéneas y actantes: El giro postsocial de la teoría del actor-red». AIBR. Revista de Antropología Iberoamericana. Número especial (novembre-desembre) [en línia] <http://www.aibr.org/antropologia/44nov/articulos/nov0512.pdf> [Consulta: 23 de juliol de 2007]

Vitores, Anna (2001). «Ressenya de Domènech, M. y Tirado, F. J. (comps.) (1998). Sociología simétrica. Barcelona: Gedisa" Athenea Digital. Revista de Pensamiento e Investigación social, núm. 0 [en línia] <http://psicologiasocial.uab.es/athenea/ index.php/atheneaDigital/article/view/11/11> [Consulta: 23 de juliol de 2007] 